\title{
Gonadotrophins and sex steroids during pregnancy and natural superfoetation in captive brown hares (Lepus europaeus)
}

\author{
M. Caillol ${ }^{1}$, M. Mondain-Monval ${ }^{2}$ and B. Rossano ${ }^{1}$ \\ ${ }^{1}$ Institut National de la Recherche Agronomique, Laboratoire de Physiologie Sensorielle, 78352 \\ Jouy-en-Josas Cedex, France; and ${ }^{2}$ Fondation de Recherche en Hormonologie, 67-77 Boulevard \\ Pasteur, 94260 Fresnes, France
}

\begin{abstract}
Summary. In brown hares, which are induced ovulators, sexual behaviour occurs episodically at the beginning of pregnancy. From Day 34 (length of pregnancy is 41 days), the frequency of sexual chases followed by mating, ovulation and fertilization increased and $59 \%$ of pregnant females presented a natural superfoetation. The pattern of circulating luteinizing hormone ( $\mathrm{LH}$ ), follicle-stimulating hormone (FSH), oestradiol and progesterone was studied in 13 pregnant females left permanently with a male, and in 10 females isolated from males around Day 20 of pregnancy. In the 2 groups, FSH concentrations were high at the beginning and end of pregnancy. All females presented a peak value of FSH in the last 4 days of pregnancy, regardless of mating stimuli. This peak value was higher for females left permanently with a male than for isolated ones. Oestradiol concentrations fluctuated between 20 and $100 \mathrm{pg} / \mathrm{ml}$, without any clear correlation with sexual behaviour, stage of pregnancy or profiles of other hormones. Prepartum matings occurred when progesterone values were still $>50 \mathrm{ng} / \mathrm{ml}$; they were followed by a transient rise in $\mathrm{LH}$ and by a periovulatory progesterone secretion, with values above $100 \mathrm{ng} / \mathrm{ml}$ in the morning after mating. Such modifications of $\mathbf{L H}$ and progesterone were not detected before Day 34, suggesting that mating stimuli are not able to induce an LH surge at the beginning of pregnancy. After Day 34, mating can induce an LH surge, ovulation and superfoetation.
\end{abstract}

Keynords: brown hare; sexual behaviour; pregnancy; superfoetation; steroids; gonadotrophins

\section{Introduction}

Natural superfoetation, defined as ovulation, fertilization and implantation of a second set of eggs during pregnancy (Rollhauser, 1949), is very rare among mammals. It has been described in some hystricomorph (Weir, 1974) and ctenodactyl rodents (Gouat, 1985), but no information is available on the hormonal conditions allowing ovulation in pregnant females.

Female hares (Lepus europaeus) are induced ovulators. Although pregnancy lasts 41 days, the interval between 2 successive parturitions is often shorter, because mating, ovulation and fertilization occur some days before parturition, leading to a natural superfoetation (Hediger, 1948; Martinet, 1980). In a previous study, we showed that prepartum matings and ovulations occur, in brown hares, when progesterone concentrations are still high, without any clear increase in oestrogen values (Caillol \& Martinet, 1979). No data are available concerning the pattern of gonadotrophins in relation to sex steroids in pregnant females either left with a male and presenting a prepartum mating and a superfoetation, or isolated from the male and therefore not ovulating. The aim of the present paper was to study the hormonal conditions allowing sexual behaviour and ovulation at the end of pregnancy, and thus superfoetation. 


\section{Materials and Methods}

Animals. Female hares were born in captivity and maintained all the year round in rooms with controlled lighting ( $14 \mathrm{~h}$ light: $10 \mathrm{~h}$ dark) to suppress seasonal anoestrus (Martinet, 1976). When 5 months old, they were put with a male in a $3 \mathrm{~m}^{2}$ wooden pen with a wire-netting floor and roof.

Sexual behaviour was recorded in 537 pregnant females kept permanently with a male. Sexual chases, followed or not by mating and intromission, are often long and violent and usually take place during the night; they were revealed by the presence of tufts of hair in the cages. As matings could rarely be observed and could not be interrupted for blood sampling or other experimental purposes because of pregnancy failures, the period of sexual receptivity was deduced from the date of the subsequent parturition (Caillol \& Martinet, 1983).

For the study of hormonal profiles during pregnancy and superfoetation, hares were assigned to 2 groups. In the first group, 13 pregnant females were left permanently with a male; among these females, 10 presented a prepartum mating followed by a superfoetation on Day 38 ( 3 females), 39 ( 4 females) or 40 (3 females); one female mated on Day 39 , but with no resulting pregnancy; in the remaining 2 females, no signs of sexual behaviour were noted at the end of pregnancy. In the second group, 10 pregnant females were isolated from the male as soon as pregnancy was detected by abdominal palpation, around Day 20 , so that superfoetation could not occur.

Blood samples $(\sim 5 \mathrm{ml})$ were withdrawn between 09:00 and 10:00 h every morning during pregnancy from ear veins of unanaesthetized animals. Serum samples were prepared after centrifugation at $4^{\circ} \mathrm{C}(5000 \mathrm{~g})$ and stored frozen until assayed.

Measurement of luteinizing hormone, follicle-stimulating hormone, progesterone and oestradiol-17ק, Luteinizing hormone ( $\mathrm{LH})$ and follicle-stimulating hormone (FSH) were measured as described by Mondain-Monval et al. (1985) and Caillol et al. (1990). Serum concentrations of LH were determined in duplicate 200- $\mu$ l aliquots, using a rabbit anti-ovine LH antiserum (GDN 15), a highly purified ovine LH (LER 1056-C2) as tracer and a canine LH (LER 16851) as standard. The sensitivity of the $\mathrm{LH}$ assay was $0.4 \mathrm{ng} / \mathrm{ml}$, and intra- and interassay coefficients of variation were 4 and $6 \%$, respectively.

Serum concentrations of FSH were determined in duplicate 150- $\mu$ l aliquots, using a rabbit anti-human FSH antiserum (M 94), a highly purified ovine FSH (LER-1976 A2) as tracer and a canine FSH (LER-1685 3A) as standard. The sensitivity of the FSH assay was $20 \mathrm{ng} / \mathrm{ml}$, and intra- and interassay coefficients of variation were 6.0 and $10.6 \%$, respectively.

Progesterone and oestradiol-17 $\beta$ were measured according to Caillol \& Martinet (1976) and Stoufflet \& Caillol (1988). Nonradioactive steroids were purchased from Steraloids (Wilton, NH 03086, USA); radioactive steroids were obtained from the Comissariat à l'Energie Atomique (Saclay, France). Merck analytical-grade solvents were used without redistillation. Bound and free fractions were separated using a dextran-charcoal mixture. Blank values, run with each assay, were below the assay sensitivity.

Progesterone assay was performed after hexane extraction of $100 \mu \mathrm{l}$ serum. The antiserum was highly specific, the major cross-reactions being $7.5 \%$ with deoxycorticosterone and $5 \alpha$-pregnane-3,20-dione. The sensitivity of the progesterone assay was $25 \mathrm{pg}$ for the standard curve $(2.5 \mathrm{ng} / \mathrm{ml}$ serum $)$, and intra- and interassay coefficients of variation were 7.0 and $8.5 \%$, respectively.

Oestradiol was measured after diethyl ether extraction of $1 \mathrm{ml}$ serum and chromatography on Sephadex LH 20 microcolumns $(5 \mathrm{~cm}$ high; benzen-ethanol $85 / 15 \mathrm{v} / \mathrm{v}$ as eluant) (Castanier \& Scholler, 1970). The sensitivity of the oestradiol assay was $3 \mathrm{pg}$ for the standard curve $(20 \mathrm{pg} / \mathrm{ml} \mathrm{serum})$, and intra- and interassay coefficients of variation were 6.0 and $10.3 \%$, respectively.

Statistical analysis. Basal LH concentrations remained very low during pregnancy and showed little variation, but FSH concentrations fluctuated widely during pregnancy. To detect possible peak values, a mean FSH baseline was calculated by the smoothing procedure called lowest, according to Chambers et al. (1983). A peak of LH or of FSH was considered significant if there was an increment of at least $3.7 \times$ the intra-assay coefficient of variation of the assay between the baseline and the highest value, according to Solari (1983).

Hormonal concentrations were expressed as means \pm s.e.m. At the end of pregnancy, mean FSH and LH concentrations were compared in the 2 experimental groups by repeated-measures analysis of variance, followed by analysis of variance of contrast variables (univariate tests of hypothesis for within-subject effects to detect the successive differences between days).

To describe the hormonal profiles characteristic of superfoetation, for females left permanently with a male and presenting a prepartum mating, the hormonal data were normalized to the day of the LH peak (considered as Day 41 of pregnancy) and analysed by repeated-measures analysis of variance followed by analysis of variance for contrast variables (univariate tests of hypothesis for within-subject effects to detect differences from Day 41). All these analyses were performed using SAS procedures (SAS/STAT Guide for Personal Computers, Version 6 Edition, 1987, SAS

Institute Inc., SAS Circle, Box 8000, Cory NC 27512, 8000).

\section{Sexual behaviour during pregnancy}

\section{Results}

Evidence of at least one sexual chase was noted in 377 pregnancies out of 531 . These sexual chases never resulted in a pregnancy before Day 34 . The proportion of fertile matings followed by a superfoetation was greatest between Days 38 and 40 (Fig. 1). 


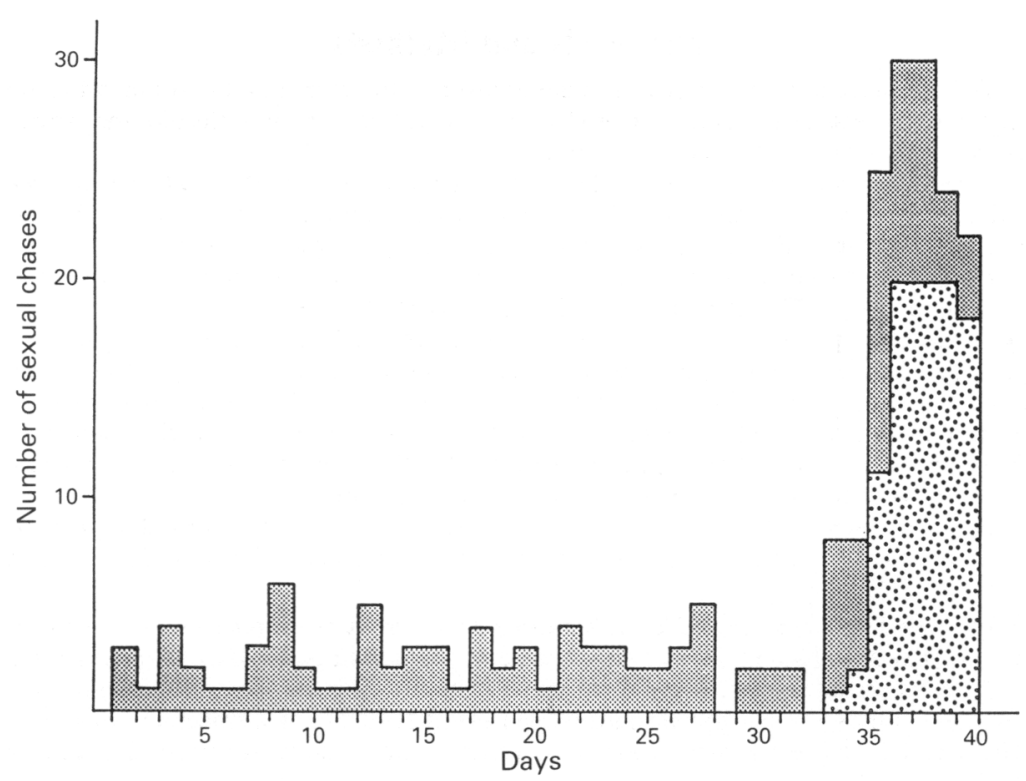

Fig. 1. Number of sexual chases, deduced from tufts of hair found under the cages (圈), and of fertile matings, deduced from a parturition 41 days later (․․ in 537 pregnant, female brown hares.

\section{LH, FSH and progesterone concentrations in pregnant females left permanently with a male}

LH remained at a basal concentration during the whole pregnancy and showed a peak $(31.24 \pm 15.41 \mathrm{ng} / \mathrm{ml}$, range $1.9-145 \mathrm{ng} / \mathrm{ml})$, the day of the prepartum mating normalized to Day 41 of the first pregnancy, and considered as Day 0 of the new one (Fig. 2). These prepartum matings inducing an LH peak occurred 1-3 days before parturition, when circulating progesterone was $\sim 60 \mathrm{ng} / \mathrm{ml}$. An acute progesterone rise occurred on the day of prepartum mating, with mean values of $142 \pm 15 \mathrm{ng} / \mathrm{ml}$. Such changes in LH and progesterone concentrations were not observed when sexual chases occurred before Day 35 .

FSH concentrations increased rapidly at the beginning of pregnancy and showed a peak on Day 5 , when progesterone concentrations were low. They remained high until Day 16 and decreased thereafter until the last days of pregnancy. Mean FSH concentrations showed a significant rise on the day of the LH peak $(P<0 \cdot 01)$, remained high for 3 days and decreased around parturition.

Parturition occurred 1-3 days after the LH peak, when progesterone values were low.

\section{LH, FSH and progesterone in females isolated from the male at midpregnancy}

In the absence of a male, there were no peaks of $\mathrm{LH}$ or progesterone at the end of pregnancy (Fig. 3). However, as in females kept with a male, FSH concentrations rose significantly in the last 3 days of pregnancy $(P<0.05)$, but with significantly lower values $(P<0.01)$.

\section{Steroid and gonadotrophin profiles in $\mathbf{2}$ individual females}

To give more-precise data on the relationships between mating, ovulation, parturition and hormonal environment, individual profiles of progesterone, oestradiol-17 $\beta$, LH and FSH were followed during 2 pregnancies, one resulting from a prepartum mating on Day 39 (Fig. 4a) and the other from mating in a nonpregnant, nonpseudopregnant female. In the latter, a prepartum mating occurred on Day 39, followed by a superfoetation (Fig. 4b). 

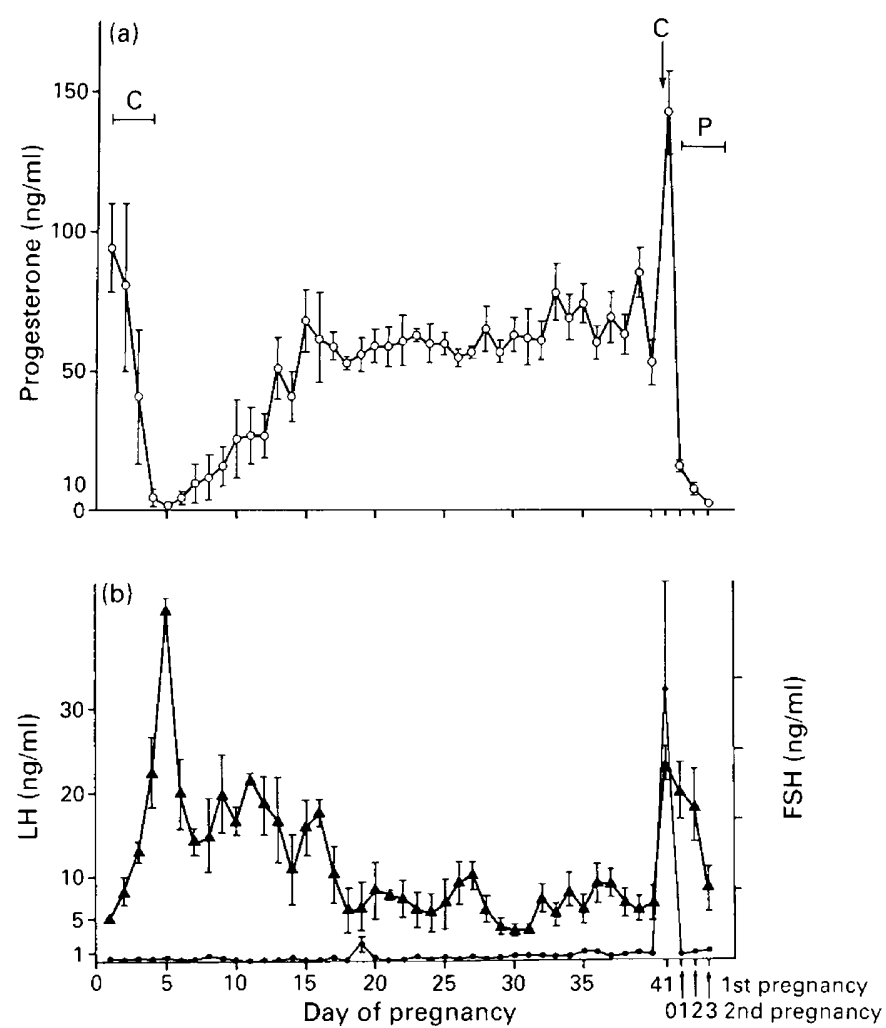

Fig. 2. Concentrations of (a) progesterone and (b) luteinizing hormone (LH, $)$ and folliclestimulating hormone ( $\mathrm{FSH}, \mathbf{\Delta})$ during pregnancy in 11 female brown hares left permanently with a male and showing a prepartum mating on Day $41 ; \mathrm{P}=$ parturition, $\mathrm{C}=$ coitus. Values are means \pm s.e.m.

Oestradiol concentrations fluctuated between 20 and $100 \mathrm{pg} / \mathrm{ml}$, without any clear relation with sexual behaviour, stage of pregnancy or profiles of other hormones. Mating induced an LH peak and progesterone release in both the nonpregnant, nonpseudopregnant female and in females at the end of pregnancy. Several FSH peaks were observed (Fig. 4); the mean interval between FSH peaks was 5.75 \pm 1.9 days (range 3-11 days). At the time of ovulation, LH and FSH peaks were dissociated.

\section{Discussion}

Our results show that in brown hares, natural superfoetation is possible because mating towards the end of pregnancy is able to induce a gonadotrophin surge and ovulation.

In most mammals, high concentrations of circulating progesterone during luteal phases or pregnancies inhibit sexual behaviour. In pregnant hares, fertile matings leading to superfoetation were possible from Day 34, with an increased frequency between Days 38 and 40, when progesterone values are still very high; $85 \%$ of pregnant hares mated and ovulated at the end of pregnancy; among these, 59\% exhibited superfoetation (Caillol \& Martinet, 1983). Before Day 34 of pregnancy, sexual chases were never able to induce an ovulation or superfoetation. Unfortunately, we do not know whether all sexual chases were followed by copulation in this study, but Lincoln (1974) reported the presence of sperm in the cervical smears of females at midpregnancy. This suggests that, at least on some occasions, intromission may occur before Day 34. In doe rabbits, 


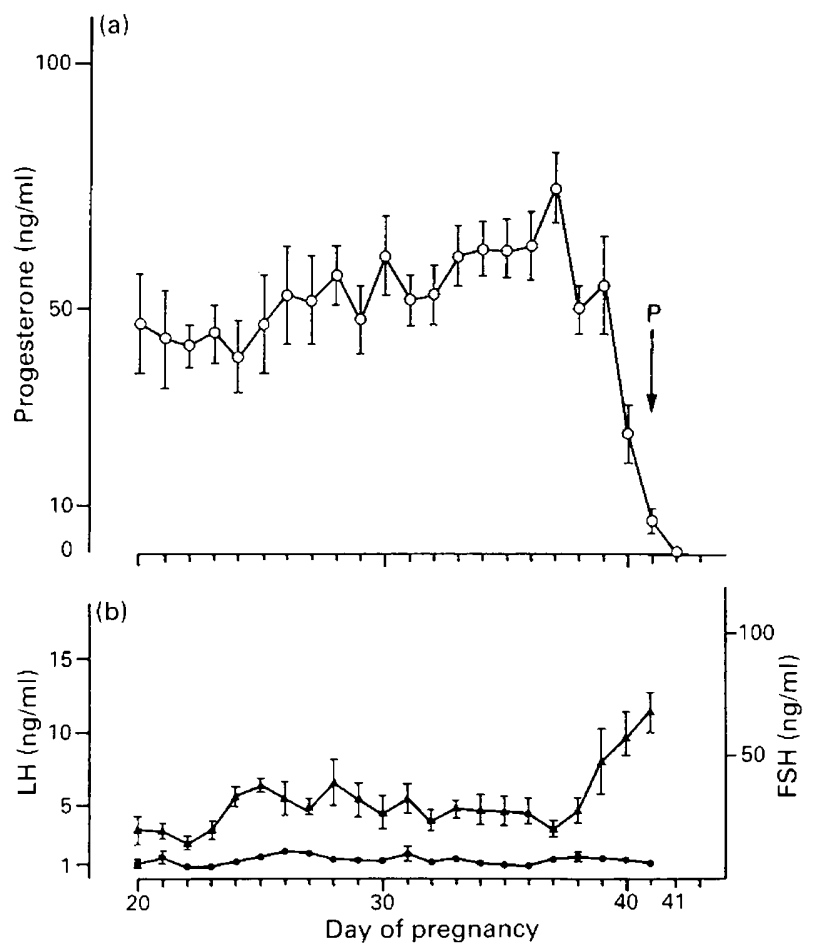

Fig. 3. Concentrations of (a) progesterone and (b) luteinizing hormone ( $\mathrm{LH}, \mathbf{0})$ and folliclestimulating hormone (FSH, $\boldsymbol{\Delta}$ ) during pregnancy in 10 female brown hares isolated from the male around Day $20 ; \mathrm{P}=$ parturition. Values are means \pm s.e.m.

sexual behaviour followed by mating and intromission remains possible during the whole pregnancy, even when progesterone values are high, but never induces ovulation or superfoetation (Hammond \& Marshall, 1925). Nevertheless, the frequency of receptive doe rabbits increases at the end of pregnancy, when progesterone concentrations have decreased (Stoufflet \& Caillol, 1988). Such an inverse relationship between progesterone concentration and sexual behaviour does not exist in brown hares, in which concentrations of circulating oestradiol remained below $100 \mathrm{pg} / \mathrm{ml}$ throughout pregnancy, and were not related to the appearance of sexual receptivity. However, the number of Graafian follicles increases as pregnancy progresses (Martinet, 1980), suggesting increased oestrogenic activity, which could be responsible for the increased frequency of sexual chases and mating at the end of pregnancy.

In brown hares, we have shown that FSH concentrations were high at both the beginning and end of pregnancy, with some episodic fluctuations with a mean interval between peak values of $\sim 6$ days. This could be related to waves of follicular growth persisting during pregnancy, as suggested in other species. In rabbits, there is a depletion of large follicles 2 days after ovulation, with a subsequent repopulation of the ovaries with large follicles by Day 6 (Osteen \& Mills, 1980); follicular growth is not interrupted during pregnancy (Hammond \& Marshall, 1925; Hill \& Parkes, 1932; Adams, 1968). In pregnant ewes, Bister \& Paquay (1983) found an endogenous rhythm for FSH secretion and suggested a close relation with waves of follicular growth.

In brown hares, FSH profiles at the end of pregnancy were similar for females left permanently with a male or isolated from the male around Day 20. In both groups, there was a peak of FSH in the last 4 days of pregnancy; this peak concentration was therefore not due to mating stimuli and thus did not depend on any presumed ovulatory surge of LH-releasing hormone (LHRH). Nevertheless, the mean FSH peak value was significantly higher for females left permanently with 

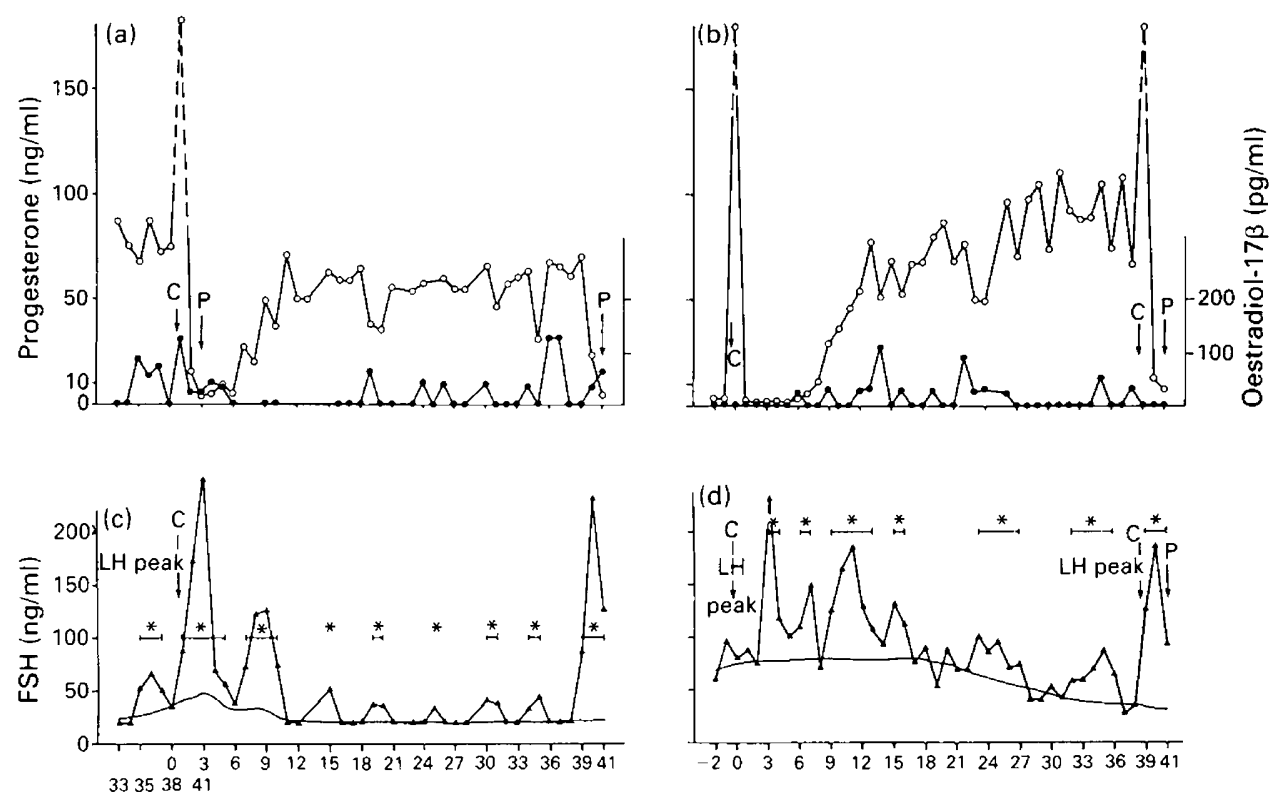

Day of pregnancy

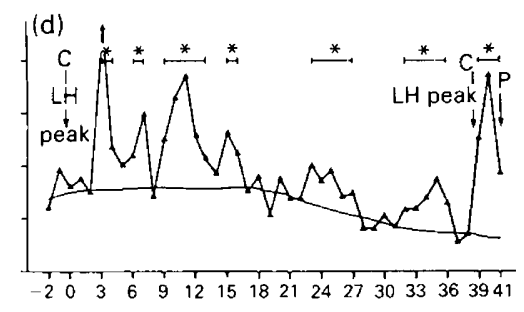

Day of pregnancy

Fig. 4. Concentrations of (a and b) progesterone $(O)$ and oestradiol-17 $\beta$ (O) and (c and d) follicle-stimulating hormone (FSH, $\boldsymbol{\Delta}$ ) in 2 pregnant, female brown hares. In (a) and (c), the pregnancy resulted from a prepartum mating on Day 38 . In (b) and (d), the pregnancy resulted from mating of a nonpregnant, nonpseudopregnant female; at the end of this pregnancy, a prepartum mating occurred on Day $39 ; \mathrm{P}=$ parturition, $\mathrm{C}=$ coitus. For $\mathrm{FSH}$, a mean baseline $(\longrightarrow$ ) was calculated by the smoothing method called the lowest; $\longmapsto$ : values significantly higher than the baseline $(P<0 \cdot 01)$; ${ }^{*}$ FSH peaks.

a male than for isolated ones, and could reflect an increased secretion of LHRH due to the presence of the male. A similar mechanism has been observed in another induced ovulator, the prairie vole: the introduction of a male is followed within minutes by an increase in LHRH concentrations in the olfactory bulb tissue (Dluzen et al., 1981).

LH concentrations remained basal during the whole pregnancy in female hares kept permanently with a male as well as in isolated ones. From Day 34, prepartum matings were followed by a transient rise in LH concentrations. The great variability observed in the height of the $\mathrm{LH}$ peak was probably due to the short duration of this peak $(<24 \mathrm{~h})$. The maximum peak value reported was $145 \mathrm{ng} / \mathrm{ml}$, and did not differ from the peak reached $15 \mathrm{~min}$ after an LHRH injection in nonpregnant, nonpseudopregnant hares during the breeding season (Caillol et al., 1986).

The prepartum peaks of LH and FSH were dissociated. In 10 females out of 11, an FSH peak occurred in the $48 \mathrm{~h}$ following the $\mathrm{LH}$ peak induced by mating; this could correspond to the second rise in FSH concentrations related to ovulation described in nonpregnant, nonpseudopregnant females after LHRH injection (Caillol et al., 1990). A similar postovulatory surge of FSH has been described in rabbits after mating; this was not mediated by LHRH, but might be triggered by ovarian factors other than oestradiol (Osteen \& Mills, 1979; Meunier et al., 1983; Mills et al., 1983; Mills \& Copland, 1983).

In brown hares, the LH surge induced by mating in nonpregnant, nonpseudopregnant females as well as in pregnant ones was followed by a transient marked rise in progesterone concentration, with values still $>100 \mathrm{ng} / \mathrm{ml}$ in the morning after mating. This progesterone secretion probably originated from the large amount of interstitial tissue (Caillol et al., 1986). Such rises in progesterone concentration, as well as significant increases in LH values, were not detected before Day 34, 
suggesting that sexual chases and mating at the beginning of pregnancy were not able to induce an LH surge. A similar finding has been obtained in pregnant rabbits during the whole pregnancy (Mills \& Gerardot, 1984), leading to the conclusion that progesterone probably blocked LHRH release in response to mating (Hilliard et al., 1971). Furthermore, in rabbits, the LH response to LHRH was reduced during pregnancy or pseudopregnancy (Hilliard et al., 1971; Carlson \& Perrin, 1979). However, in brown hares (Martinet, 1980), as in rabbits (Stormshak \& Casida, 1965), the ovary remains able to respond to an injection of human chorionic gonadotrophin by an ovulation during the whole pregnancy. So, in brown hares, the ovulation induced by mating was blocked until Day 34, either because the pituitary was not able to respond to an LHRH surge by a gonadotrophin secretion and/or because mating stimuli were not able to induce an LHRH surge. After Day 34, the neuroendocrine pathway between mating stimuli and ovulation was re-established, allowing natural superfoetation. A possible explanation is that there is a rise of circulating oestrogens at the end of pregnancy, allowing an increased frequency of mating behaviour, and an appropriate response of the hypothalamus - pituitary-ovarian axis to the natural stimulus of coitus. In doe rabbits, such an essential role of oestradiol in the maintenance of the neural pathways between mating and ovulation has been suggested (Ramirez \& Beyer, 1988).

Further work is necessary to define the precise site of action of the presumed progesterone blockade (pituitary and/or hypothalamus) up to Day 34 of pregnancy, and the mechanisms overriding this blockade after this time.

We thank Miss A. Solari for help with statistics, Mr M. Carpentier and Mr G. Oxaran for skilful care of the animals, Dr G. D. Niswender (College of Veterinary Medicine and Biomedical Sciences, Dept of Physiology and Biophysics, Colorado State University, Fort Collins, CO 80523, USA) for the LH GDN 15 antiserum, Dr A. S. McNeilly (MRC Reproductive Unit, 37 Chalmers Street, Edinburgh EH3 9EW, UK) for the FSH M 94 antiserum, Dr L. E. Reichert (Dept of Biochemistry, Albany Medical College, Albany, NY 12208) for the ovine LH and FSH, and canine pituitary standards, and Dr R. Scholler for facilities to perform hormone assays in the laboratories of the Fondation de Recherche en Hormonologie.

\section{References}

Adams, C.E. (1968) Ovarian response to human chorionic gonadotrophin and egg transport in the pregnant and post-parturient rabbit. J. Endocr. 40, $101-105$.

Bister, J.L. \& Paquay, R. (1983) Fluctuations in the plasma levels of the follicle-stimulating hormone during estrous cycle, anestrus, gestation and lactation in the ewe: evidence for an endogenous rhythm of FSH release. Theriogenology 19, 565-582.

Caillol, M. \& Martinet, L. (1976) Preliminary results on plasma progesterone levels during pregnancy and superfetation in the hare, Lepus europaeus. J. Reprod. Fert. 46, 61 -64.

Caillol, M. \& Martinet, L. (1979) Estrous behavior, follicular growth and pattern of circulating sex steroids during pregnancy and pseudopregnancy in the captive brown hare. In Proc. Wld Lagomorph Conf. Guelph, pp. 142-154. Eds K. Myers \& C. D. McInnes. Univ. Guelph, Guelph, Ontario, Canada.

Caillol, M. \& Martinet, L. (1983) Mating periods and fertility in the doe hare (Lepus europaeus) bred in captivity. Acta. Zool. Fennica 174, 65-68.

Caillol, M., Meunier, M., Mondain-Monval, M. \& Simon, P. (1986) Seasonal variations in the pituitary response to LHRH in the brown hare, Lepus europaeus. $J$. Reprod. Fert. 78, 479-486.

Caillol, M., Mondain-Monval, M. \& Meunier, M. (1990) Effect of ovariectomy at two periods of the year on LH and FSH basal concentrations and pituitary response to LHRH in the brown hare (Lepus europaeus). J. Reprod. Fert. 88, 533-542.

Carlson, J.C. \& Perrin, D.G. (1979) The effect of LHRH administration on $\mathrm{LH}$ release in the female rabbit. $J$. Reprod. Fert. 56, $175 \cdot 180$.

Castanier, M. \& Scholler, R. (1970) Dosage radioimmunologique de l'oestrone et de l'oestradiol-17 $\beta$ plasmatiques. C. R. Acad. Sci. Paris, D 271, 1787-1789.

Chambers, J.B., Cleveland, W.S., Kleiner, B. \& Tukey, P.A. (1983) Graphical Methods for Data Analysis. Eds Wadsworth \& Brooks. Cole Statistics/Probability series.

Dluzen, D.E., Ramirez, V.D., Carter, C.S. \& Getz, L.L. (1981) Male vole urine changes luteinizing hormonereleasing hormone and norepinephrine in female olfactory bulb. Science, N.Y. 212, 573-575.

Gouat, J. (1985) Notes sur la reproduction de Ctenodactylus gundi, rongeur Ctenodactylidae. $Z$. Säugetierkunde 50, 285-293. 
Hammond, J. \& Marshall, F. (1925) Reproduction in the Rabbit. Oliver and Boyd. Edinburgh.

Hediger, H. (1948) Die Zucht des Feldhasen (Lepus europaeus Pallas) in Gefangenschaft. Physiol. Comp. Oecol. 1, $46-62$.

Hill, M. \& Parkes, A.S. (1932) The relation between the anterior pituitary body and the gonads. IV. Induction of ovulation during pregnancy and its effects on fetuses. Proc. R. Soc., B. 110, 180-186.

Hilliard, J., Schally, A.V. \& Sawyer, C.H. (1971) Progesterone blockade of the ovulatory response to intrapituitary infusion of LHRH in rabbits. Endocrinology 88, 730-736.

Lincoln, G.A. (1974) Reproduction and March madness in the brown hare, Lepus europaeus. J. Zool., Lond. 174, $1-14$.

Martinet, L. (1976) Seasonal reproduction cycles in the European hare raised in captivity. Role of photoperiodicity. In Ecology and Management of European Hare Populations, pp. 55 57. Eds Z. Pielowski \& Z. Pucek. Polish Hunting Association, Warsaw.

Martinet, L. (1980) Oestrous behaviour, follicular growth and ovulation during pregnancy in the hare (Lepus europaeus). J. Reprod. Fert. 59, 441-445.

Meunier, M., Hulot, F., Poirier, J.C. \& Torres, S. (1983) A comparison of ovulatory gonadotropic surge in two rabbit strains: no evidence for a relationship between LH or FSH surge and factors of prolificacy. Reprod. Nutr. Develop. 23(4), 709-715.

Mills, T.M. \& Copland, J.A. (1983) Effects of castration and estradiol treatment on the postovulatory secretion of follicle-stimulating hormone in the mated rabbit. Biol. Reprod. 28, 306-311.

Mills, T.M., Copland, J.A., Coy, D.H. \& Schally, A.V. (1983) Is the postovulatory release of follicle-stimulating hormone in the rabbit mediated by luteinizing hormone releasing hormone? Endocrinology 113, 1020-1024.
Mills, T.M. \& Gerardot, R.J. (1984) Dissociation of copulation from ovulation in pregnant rabbits. Biol. Reprod. 30, 1243-1252.

Mondain-Monval, M., Caillol, M. \& Meunier, M. (1985) Heterologous radioimmunoassay of $\mathbf{L H}$ in two seasonally breeding animals: hare (Lepus europaeus) and mink (Mustela vison). Can.J. Zool. 63, 1339-1344.

Osteen, K.G. \& Mills, T.M. (1979) Serum LH and FSH levels in the pregnant rabbit. Proc. Soc. Exp. Biol. Med. 162, 454-457.

Osteen, K.G. \& Mills, T.M. (1980) Changes in the size, distribution and steroid content of rabbit ovarian follicles during early pseudopregnancy. Biol. Reprod. 22, $1040-1046$.

Ramirez, V.D. \& Beyer, C. (1988) The ovarian cycle of the rabbit: its neuroendocrine control. In The Physiology of Reproduction, pp. 1873-1892. Eds E. Knobil, J. Neill, L. Ewing, G. Greenwald, C. Markert \& D. Pfaff. Raven Press Ltd, New York.

Rollhauser, H. (1949) Superfetation in mouse. Anat. Rec. $105,657-663$.

Solari, A. (1983) Utilisation des plasmas de référence pour l'estimation de la précision des mesures des dosages radioimmunologiques. Reprod. Nutr. Develop. 23, $\mathrm{I}-12$.

Stormshak, F. \& Casida, L.E. (1965) Effects of LH and ovarian hormones on corpora lutea of pseudopregnant and pregnant rabbits. Endocrinology 77, 337-342.

Stoufflet, I. \& Caillol, M. (1988) Relation between circulating sex steroid concentrations and sexual behaviour during pregnancy and post partum in the domestic rabbit. J. Reprod. Fert. 82, 209-218.

Weir, B.J. (1974) Reproductive characteristics of hystricomorph rodents. Symp. Zool. Soc. London 34, 265-301.

Received 13 April 1990 